\title{
Produção da hortelã-japonesa em função da adubação orgânica no plan- tio e em cobertura
}

\author{
Jorge H Chagas; José Eduardo BP Pinto; Suzan KV Bertolucci; Fúlvia M Santos; Priscila P Botrel; \\ Luciano BB Pinto \\ UFLA-DAG, C. Postal 3037, 37200-000 Lavras-MG; jeduardo@dag.ufla.br
}

\begin{abstract}
RESUMO
Objetivou-se avaliar os efeitos da adubação orgânica no plantio e em cobertura na produção de biomassa seca da parte aérea e no teor e rendimento de óleo essencial da hortelã-japonesa (Mentha arvensis L.). $\mathrm{O}$ experimento constou de duas etapas (colheitas). $\mathrm{O}$ delineamento utilizado foi em blocos ao acaso, com três repetições. $\mathrm{Na}$ primeira etapa, foram avaliadas cinco diferentes doses de esterco bovino aplicadas às parcelas no plantio $\left(0 ; 2,5 ; 5,0 ; 7,5 \mathrm{e} 10,0 \mathrm{~kg} \mathrm{~m}^{-2}\right) \mathrm{e}$ após 120 dias de cultivo foi realizada a primeira colheita. Na segunda etapa, após a primeira colheita, as parcelas foram subdivididas em quatro subparcelas, às quais foram aplicadas quatro doses de esterco bovino em cobertura $\left(0 ; 2,5 ; 5,0\right.$ e 7,5 $\left.\mathrm{kg} \mathrm{m}^{-2}\right)$, obedecendo um arranjo de parcelas subdivididas. A segunda colheita foi realizada 120 dias após a primeira. $\mathrm{O}$ material vegetal foi seco em estufa a $37^{\circ} \mathrm{C}$ e o óleo essencial foi extraído em aparelho de Clevenger. A biomassa seca da parte aérea $(\mathrm{g})$, o teor percentual $(\mathrm{p} / \mathrm{p})$ e o rendimento de óleo essencial foram determinados. Os níveis de esterco bovino aplicados tanto no plantio como em cobertura, afetaram de forma linear positiva a produção de biomassa seca da parte aérea e o rendimento de óleo essencial. O teor de óleo essencial não foi afetado pelos diferentes níveis de adubação orgânica.
\end{abstract}

Palavras-chave: Mentha arvensis L., planta medicinal, óleo essencial, biomassa seca, esterco bovino.

\begin{abstract}
Production of mint depending on organic manure at planting and dressing

This study aimed to evaluate the effects of organic fertilization at planting and dressing on the aboveground part dry biomass and on the content and yield of essential oil of mint (Mentha arvensis). The experiment consisted of two stages (harvests). A randomized complete block design was used, with three replications. At the first stage, five different cattle manure dosages $(0,2.5,5.0,7.5$ and 10.0 $\mathrm{kg} \mathrm{m}^{-2}$ ) applied to the plots at planting, were evaluated and the first harvest was carried out 120 days later. At the second stage after the first harvest, the plots were subdivided in four split-plot and four cattle manure dosages $\left(0,2.5,5.0\right.$ and $\left.7.5 \mathrm{~kg} \mathrm{~m}^{-2}\right)$ were applied at dressing, following a split-plot design. The second harvest was carried out 120 days after the first one. The fresh biomass was dried in the oven at $37^{\circ} \mathrm{C}$ and the essential oil was extracted in a Clevenger apparatus. Aboveground part dry biomass (g), essential oil content $(\mathrm{w} / \mathrm{w} \%)$ and essential oil yield were determined. The levels of cattle manure applied at planting and dressing affected in a positive linear way the aboveground part dry biomass production and the essential oil yield. Essential oil content was not affected by different organic manure levels.
\end{abstract}

Keywords: Mentha arvensis L., medicinal plant, essential oil, dry biomass, cattle manure.

(Recebido para publicação em 14 de maio de 2010; aceito em 12 de julho de 2011)

(Received on May 14, 2010; accepted on July 12, 2011)

\begin{abstract}
$\mathrm{A}^{M}$ Mentha arvensis L. é uma espécie aromática e medicinal pertencente à família Lamiaceae, conhecida popularmente como vick, hortelã-do-brasil e hortelã-japonesa. Originária do sul da China, com hábito herbáceo rizomatoso, esta planta possui propriedades terapêuticas como descongestionante nasal, na eliminação de gases do aparelho digestivo ou como sedativo do estômago, contra náuseas e vômitos. As folhas podem ser usadas frescas, secas, na forma de chá, tintura ou como inalante (Duarte et al., 2005; Ram et al., 2006).

$\mathrm{O}$ cultivo industrial da hortelã-japonesa é realizado em áreas semi-temperadas em vários países, tais como China, Índia, França, Estados Unidos e
\end{abstract}

Brasil para a hidrodestilação de seu óleo essencial. O óleo essencial de menta, o mentol cristalizado a partir do óleo essencial, o óleo essencial desmentolado e outros monoterpenos fracionados a partir do óleo desmentolado são alguns produtos comerciais dessa espécie (Srivastava et al., 2002). Esses produtos são utilizados em larga escala nas indústrias alimentícias, farmacêuticas, cosméticas e de perfumarias (Kalra et $a l ., 2004)$. Para se ter uma idéia, a produção mundial anual de óleos essenciais de espécies aromáticas é estimada entre 110.000 e 120.000 t (Kothari, 2005), e, desta quantidade, $22.200 \mathrm{t}$ vêm de espécies de Mentha: M. arvensis (16.000), M. x piperita (4.000), M. spicata (2.000) e outras (200) (Sanganeira, 2005).

No Brasil ocorreu uma redução drástica na produção de menta devido a problemas de fertilidade e manejo do cultivo em solo, uma vez que as condições nutricionais do solo são essenciais para o balanço entre acúmulo de biomassa e produção de óleo essencial, características indispensáveis para uma rentável produtividade agrícola (Paulus et al. 2007; Valmorbida \& Boaro, 2007).

As espécies de menta já foram definidas por diversos autores, como muito exigentes quanto a nutrição mineral em cultivos em solo e em hidroponia (Ram \& Kumar, 1997; Rodrigues et al., 2004; Valmorbida \& Boaro, 2007; Souza et al., 2007; Garlet et al., 2007). Dentre as 
práticas agronômicas de manejo da fertilidade do solo, a calagem e a adubação destacam-se como as mais tradicionais. Atualmente, além da adubação mineral, preconiza-se o uso da adubação orgânica, não apenas como parte essencial dos chamados cultivos orgânicos, mas pelos inúmeros benefícios decorrentes da aplicação de resíduos orgânicos ao solo (Oliveira Júnior et al., 2006).

Dentre as vantagens da fertilização orgânica citam-se a manutenção da umidade, da fertilidade e da estrutura física do solo, o favorecimento do controle microbiológico e a dinâmica de nutrientes, o que afeta favoravelmente nos rendimentos da produção vegetal (Chattopadhyay et al., 1993; Ram \& Kumar, 1997). A adubação orgânica representa também uma alternativa interessante, especialmente como opção para a pequena propriedade, com potencial de aplicação em áreas cultivadas com plantas medicinais e aromáticas, oferecendo, ao pequeno produtor, mais uma alternativa de renda e justificando a realização de estudos agronômicos e fitotécnicos em relação à produção de biomassa seca e metabólitos secundários. Assim, pode-se maximizar o potencial genético da hortelã por meio de um melhor manejo da cultura, principalmente em termos nutricionais, o que deverá proporcionar melhoria qualitativa e quantitativa do produto fornecido pelos agricultores.

O aumento da produção de biomassa seca pela incorporação de adubos orgânicos ao solo tem sido demonstrado em mentas e em diversas espécies de plantas medicinais e aromáticas tais como em Mentha arvensis L. (Singh et al., 1988; Ram \& Kumar, 1997); Mentha $x$ villosa Huds (Cruz, 1999); Catharanthus roseus (L.) G. Don (Ferreira et al., 2004); Hyptis marrubioides EPl (Sales et al., 2009); Baccharis trimera (Less) D.C (Silva et al., 2006); Ocimum selloi Benth. (Costa et al., 2008); Melissa spp. (Souza et al., 2003). Contudo, na maioria desses trabalhos realizados com adubação orgânica, de um modo geral, avaliou-se apenas a adubação de plantio. Portanto, pouco se sabe sobre o efeito de adubações orgânicas em cobertura após o primeiro corte da planta. Considerando que a Mentha arvensis L. é uma espécie perene que pode ser colhida várias vezes ao ano, porém exigente em adubações sucessivas ao longo do ciclo de cultivo numa mesma área, se faz necessário avaliar as implicações da adubação em cobertura para essa espécie.

Portanto, esse estudo teve como objetivo avaliar a resposta a diferentes doses de adubação orgânica em plantio e em cobertura sobre o acúmulo de biomassa seca e o teor e rendimento por área de óleo essencial de plantas de Mentha arvensis L., cultivadas em campo nas condições do sul de Minas Gerais.

\section{MATERIAL E MÉTODOS}

O experimento foi realizado de outubro de 2005 a maio de 2006, na Fazenda Gota da Esperança pertencente ao Setor de Plantas Medicinais, Aromáticas e Condimentares do Departamento de Agricultura da Universidade Federal de Lavras $\left(21^{\circ} 14^{\prime} \mathrm{S}\right.$ e $45^{\circ} 00^{\prime} \mathrm{W}$, a 918 $m$ de altitude). Segundo a classificação climática de Koeppen (1948), o clima regional é do tipo CWa, com características $\mathrm{CWb}$, com duas estações definidas: quente e chuvosa, de outubro a março e, amena e seca, de abril a setembro.

O solo do local, classificado como Latossolo Vermelho Distroférrico (LVD), foi analisado no Laboratório de Análises de Solos da UFLA e corrigido com aplicação de calcário, cuja dose recomendada foi obtida pelo método da saturação por bases (CFSEMG, 1999). A análise de valor agronômico do esterco bovino curtido utilizado no experimento também foi realizada revelando: $\mathrm{pH}$ em água $=5,8 ; \mathrm{P}$ e $\mathrm{K}\left(\mathrm{mg} \mathrm{dm} \mathrm{dm}^{-3}\right)=0,6$ e $61 ; \mathrm{Ca}^{2+}, \mathrm{Mg}^{2+}, \mathrm{Al}^{3+}, \mathrm{H}+\mathrm{Al}\left(\mathrm{cmol}_{\mathrm{c}} \cdot \mathrm{dm}^{-3}\right)$ $=0,8 ; 0,2 ; 0,0 ; 3,6$; soma de bases $=$ 1,2 ; índice de saturação de bases $(\%)=$ 24,4; matéria orgânica $($ dag kg-1 $)=2,0$; P-remanescente $=11,2\left(\mathrm{mg} \mathrm{L}^{-1}\right)$; areia $=$ $32 \%$; silte $=10 \%$; argila $=58 \%$; classe textural argilosa.

A propagação das mudas foi realizada através de estacas apicais coletadas de matrizes de Mentha arvensis pertencentes ao Horto Medicinal da UFLA e cultivadas em bandejas de poliestireno expandido de 128 células, contendo substrato comercial Plantmax Hortali- ças $\mathrm{HT}^{\circledR}$. As mudas foram cultivadas em casa-de-vegetação, com $60 \%$ de sombreamento, por 35 dias, até atingirem cerca de $10 \mathrm{~cm}$ de altura e após a aclimatização, foram transplantadas, em fevereiro de 2006, para canteiros de 1,2 $\mathrm{m}$ de largura, em quatro fileiras, utilizando o espaçamento de $30 \mathrm{~cm}$ entre linhas e $50 \mathrm{~cm}$ entre plantas na linha.

O delineamento experimental utilizado foi de blocos casualizados, com três repetições. O experimento foi instalado e avaliado em duas etapas. $\mathrm{Na}$ primeira, com o objetivo de avaliar a adubação de plantio, foram testadas cinco diferentes doses de esterco bovino curtido $\left(0,0 ; 2,5 ; 5,0 ; 7,5\right.$ e $\left.10 \mathrm{~kg} \mathrm{~m}^{-2}\right)$ aplicadas no plantio das mudas. Cada parcela foi composta de 68 plantas no total. Foram consideradas como parcela útil as 30 plantas centrais (área útil de $4,5 \mathrm{~m}^{2}$ ). Aos 120 dias foi feita a primeira avaliação (colheita), através do corte de toda a parte aérea das plantas, rente ao solo.

Após a primeira colheita das plantas, foi instalada a segunda etapa do experimento para avaliar o efeito somatório das adubações aplicadas no plantio e em cobertura sobre a rebrota. Cada parcela da primeira etapa foi subdividida em quatro subparcelas de 2,55 $\mathrm{m}^{2}$ cada. Cada subparcela recebeu uma das quatro doses de esterco bovino curtido $(0,0$; 2,5; 5,0 e 7,5 $\mathrm{kg} \mathrm{m}^{-2}$ ) aplicadas em cobertura após o primeiro corte das plantas. Foi considerada como subparcela útil uma área central de 1,5 x 0,6 m.

Assim, nesta etapa, o experimento passa a um arranjo de parcelas subdivididas, com cinco diferentes doses de esterco bovino aplicados às parcelas no plantio das mudas e quatro doses de esterco bovino aplicados nas subparcelas em cobertura. A segunda colheita foi realizada 120 dias após a primeira. O material vegetal colhido constou de toda a parte aérea da planta colhida rente ao solo.

As colheitas foram realizadas quando as plantas se encontravam em pleno florescimento, segundo recomendações de Brilho (1969).

O esterco bovino aplicado no plantio foi incorporado e misturado à terra com enxada manual, a uma profundidade de $10 \mathrm{~cm}$ e a aplicação do esterco bovino 
em cobertura foi feita superficialmente. Os tratos culturais rotineiros, como capinas e irrigações, foram realizados conforme as necessidades das plantas e efetuados de maneira similar, a fim de não afetar o crescimento das mesmas.

Após cada colheita, o material vegetal foi acondicionado em sacos de papel Kraft e seco em estufa com circulação forçada de ar a $37 \pm 2^{\circ} \mathrm{C}$, até atingir massa constante. A biomassa seca das plantas foi aferida em balança digital, com sensibilidade $0,01 \mathrm{~g}$. Das plantas correspondentes às duas colheitas, determinaram-se a biomassa seca da parte aérea $(\mathrm{g})$ e o teor percentual $(\mathrm{p} / \mathrm{p})$ e rendimento por área $\left(\mathrm{kg} \mathrm{ha}^{-1}\right)$ do óleo essencial.

Para a determinação do teor e rendimento por área de óleo essencial, amostras da parte aérea das plantas secas foram submetidas à hidrodestilação, em aparelho de Clevenger modificado, por $1 \mathrm{~h}$, utilizando $600 \mathrm{~mL}$ de água destilada em balão de destilação com $1 \mathrm{~L}$ de capacidade. Para a purificação do óleo essencial, o hidrolato foi submetido à partição líquido-líquido em funil de separação, realizando-se três lavagens com $20 \mathrm{~mL}$ de diclorometano em cada. As frações orgânicas foram reunidas e tratadas com sulfato de magnésio anidro. Em seguida, a solução foi submetida à filtração simples para remoção do sal e mantidas, à temperatura ambiente, sob capela de exaustão em frascos escuros, tampados com papel alumínio perfurado para permitir a evaporação do solvente residual. Em seguida, a massa do óleo essencial extraído foi determinada em balança digital, com sensibilidade $0,0001 \mathrm{~g}$, e calculado seu teor percentual $(\mathrm{p} / \mathrm{p})$ na planta seca e rendimento por área $\left(\mathrm{kg} \mathrm{ha}^{-1}\right)$ de óleo essencial.

As análises dos dados foram realizadas utilizando-se o programa Sisvar ${ }^{\circledR}$, versão 4.2 (Ferreira, 2003). Os dados foram submetidos à análise de variância com teste $\mathrm{F}(\mathrm{p}<0,05)$ e aplicada a análise de regressão às médias.

\section{RESULTADOS E DISCUSSÃO}

As diferentes doses de esterco bovino curtido aplicadas no plantio influenciaram a produção de biomassa seca da parte aérea (BSPA) na primeira etapa (primeira colheita) do experimento. Foi observada resposta linear crescente da BSPA em função das diferentes doses de adubação de plantio aplicadas. Para cada $1,0 \mathrm{~kg} \mathrm{~m}^{-2}$ de adubo aplicado na parcela houve um aumento de cerca de 33,74 g na BSPA de plantas de hortelã-japonesa (Figura 1A).

Os resultados de BSPA correspondentes à segunda etapa (segunda colheita) sofreram influências de dois fatores: adubação orgânica aplicada no plantio e adubação orgânica aplicada em cobertura após a primeira colheita (Figura 1B).

A interação entre os fatores não foi significativa pelo teste $\mathrm{F}$ a $5 \%$ de probabilidade. Isto significa que a influência de cada fator ocorreu de forma independente, linear e crescente (Figura 1B). Para cada $1,0 \mathrm{~kg} \mathrm{~m}^{-2}$ de adubo orgânico aplicado no plantio, houve um incremento de 21,89 $\mathrm{g}$ subparcela ${ }^{-1}$, dentro do intervalo das dosagens estudadas (Figura 1B).

Observou-se que as plantas responderam mais efetivamente à adubação
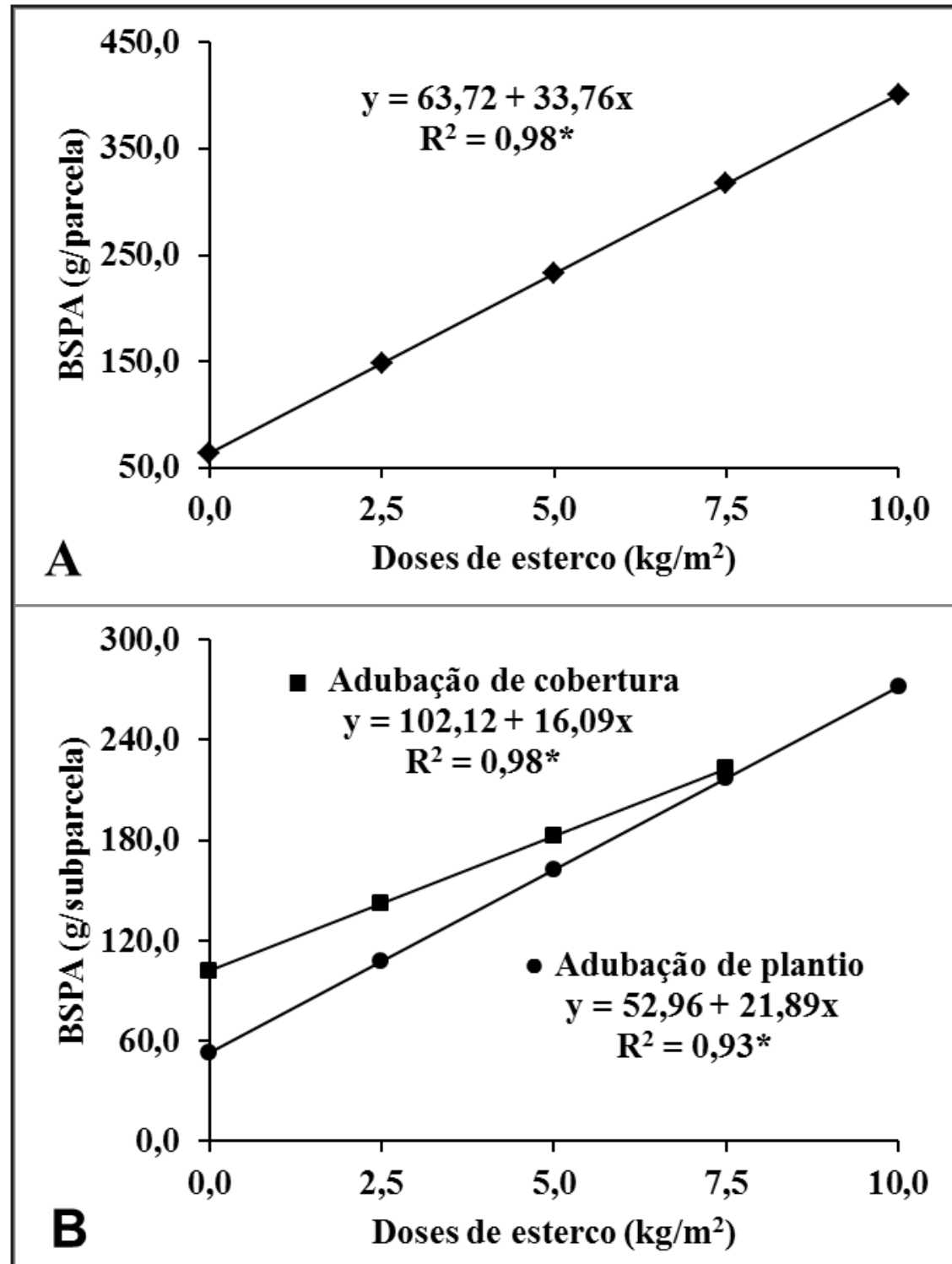

Figura 1. Efeito da adubação orgânica de plantio correspondente à primeira colheita $(\mathrm{A})$ e de plantio e cobertura correspondente à segunda colheita $(\mathrm{B})$ na biomassa seca da parte aérea (BSPA) de Mentha arvensis L. (effect of organic manure on the planting correspondent to the first harvest $(\mathrm{A})$ and on the planting and dressing correspondent to the second harvest (B) in dry biomass of aboveground part (DBAP) of Mentha arvensis L.). Lavras, UFLA, 2007. 

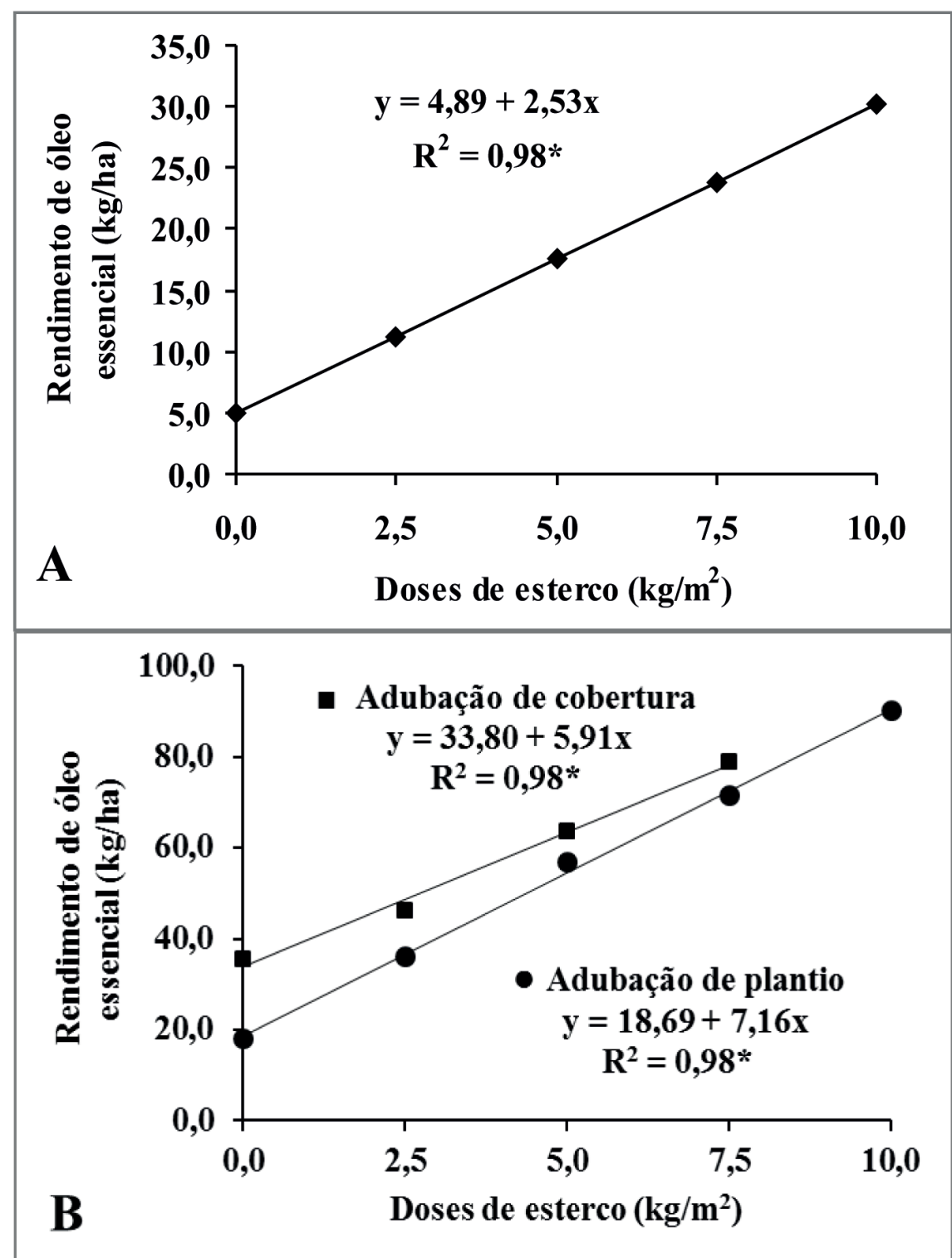

Figura 2. Efeito da adubação orgânica de plantio correspondente à primeira colheita (A) e de plantio e cobertura correspondente à segunda colheita $(\mathrm{B})$ no rendimento de óleo essencial de Mentha arvensis L. (effect of organic manure on the planting correspondent to the first harvest (A) and on the planting and dressing correspondent to the second harvest (B) in essential oil yield of Mentha arvensis L.). Lavras, UFLA, 2007.

de plantio na segunda colheita, com produtividade máxima de BSPA de $3021 \mathrm{~kg} \mathrm{ha}^{-1}$ quando comparado com a primeira colheita $892 \mathrm{~kg} \mathrm{ha}^{-1}$, na maior dose avaliada $\left(10 \mathrm{~kg} \mathrm{~m}^{-2}\right)$. Esse resultado pode estar associado à maior ocupação do solo pelas plantas de $M$. arvensis após a primeira colheita, já que elas se propagam por estolões, junto com o melhor aproveitamento dos nutrientes pelas plantas através dos benefícios físicos, químicos e biológicos da adubação orgânica ao solo.

A aplicação de doses crescentes de cando uma dose constante de $5 \mathrm{~kg} \mathrm{~m}^{-2}$ de esterco bovino no plantio e quatro doses diferentes $(0 ; 2,5 ; 5,0$ e 7,5 kg $\mathrm{m}^{-2}$ ) em cobertura. Observou-se que para cada $1 \mathrm{~kg} \mathrm{~m}^{-2}$ de esterco bovino adicionado em cobertura ao solo, obteve-se um aumento de 23,75 g de biomassa seca. Nesse mesmo estudo não se observaram diferenças significativas dos teores percentuais de óleos essenciais entre os níveis de adubação. Porém os rendimentos de óleos essenciais tiveram uma resposta linear crescente em relação a essa adubação, sendo que para cada $1,0 \mathrm{~kg} \mathrm{~m}^{-2}$ de esterco bovino adicionado em cobertura obteve-se um aumento de cerca de 5,26 $\mathrm{kg} \mathrm{ha}^{-1}$ de óleo essencial.

Em referencia ao gênero Mentha, no que tange aos objetivos do presente trabalho, foram encontrados resultados distintos na literatura. A produção de biomassa seca em plantas de Mentha arvensis, obteve resposta crescente até 6 $\mathrm{kg} \mathrm{m}^{-2}$ de adubação com esterco bovino, nos estudos de Mattos (2000). Em experimento similar, Cruz (1999) também observou para Mentha x villosa Huds. (hortelã-rasteira), produções máximas de biomassa seca com $6,0 \mathrm{~kg} \mathrm{~m}^{-2}$ de esterco bovino. Já Singh et al. (1988), em ensaios com associação de matéria orgânica e nitrogênio em Mentha arvensis L., encontraram resultados semelhantes aos obtidos no presente trabalho, em que também observaram um aumento de BSPA com os acréscimos das doses de adubo orgânico. As diferenças observadas nos resultados podem ser devido às características do solo em que foram realizados os experimentos e/ou características nutricionais inerentes ao esterco bovino utilizado. Nas análises dos solos observa-se baixa fertilidade, conforme os padrões da CFSEMG (1999), o que pode ter provocado resposta crescente e linear da biomassa seca da parte aérea em relação à adubação orgânica no plantio e em cobertura e também a independência dos efeitos da adubação orgânica de plantio em relação aos efeitos da adubação orgânica em cobertura das plantas de Mentha arvensis, uma vez que a maior disponibilidade de nutrientes no solo poderia ter reduzido o efeito da adubação de cobertura.

Não foram observadas diferenças significativas, pelo teste $\mathrm{F}$ a $5 \%$ de pro- 
babilidade, para os teores percentuais médios de óleo essencial de plantas de Mentha arvensis L. em resposta aos diferentes níveis de adubação de plantio na primeira colheita $\left(0,0 \mathrm{~kg} \mathrm{~m}^{-2}=\right.$ $2,83 \% ; 2,5 \mathrm{~kg} \mathrm{~m}^{-2}=3,10 \% ; 5,0 \mathrm{~kg} \mathrm{~m}^{-2}=$ $2,98 \% ; 7,5 \mathrm{~kg} \mathrm{~m}^{-2}=3,14 \%$ e $10,0 \mathrm{~kg} \mathrm{~m}^{-2}=$ $2,95 \%$ ), apresentando um $\mathrm{CV}=26,8 \%$.

Com relação ao teor percentual de óleo essencial da segunda colheita, também não foi observada significância na interação entre os fatores e no efeito de cada fator independente (teste $\mathrm{F}$ a $5 \%$ de probabilidade). Assim, analisando cada fator individualmente na segunda colheita, para as doses aplicadas no plantio $\left(0 ; 2,5 ; 5,0 ; 7,5\right.$ e $\left.10 \mathrm{~kg} \mathrm{~m}^{-2}\right)$ observou-se os seguintes teores médios de óleo essencial 3,08; 3,02; 3,15; 2,96 e $2,98 \%$, respectivamente. Já para as doses aplicadas em cobertura $0 ; 2,5 ; 5,0$ e $7,5 \mathrm{~kg} \mathrm{~m}^{-2}$ após a primeira colheita, obteve-se os seguintes teores médios percentuais de óleo 3,$11 ; 2,92 ; 3,13$ e $3,18 \%$ respectivamente. O coeficiente de variação foi de $23,4 \%$.

Resultados similares foram encontrados na literatura, no que se refere ao teor de óleo essencial. Singh et al. (1988), trabalhando com Mentha arvensis L., não observaram diferenças significativas no teor de óleo essencial, nos diferentes níveis de esterco bovino avaliados. Por outro lado, o teor de óleo essencial foi reduzido progressivamente nas plantas de Mentha villosa, com o aumento das doses de esterco bovino (Chaves et al., 1998). Em contraparte, incremento nos teores de óleo essencial foram observados em plantas de Hyptis marrubioides nas maiores doses de esterco bovino $\left(6,9\right.$ e $\left.12 \mathrm{~kg} \mathrm{~m}^{-2}\right)$ nos estudos de Sales et al. (2009).

No que diz respeito ao rendimento de óleo essencial, uma resposta linear crescente foi observada em relação à adubação orgânica aplicada no plantio na primeira colheita. Para cada $1,0 \mathrm{~kg}$ $\mathrm{m}^{-2}$ de esterco bovino acrescentado ao solo ocorreu um aumento de $2,53 \mathrm{~kg} \mathrm{ha}^{-1}$ de óleo essencial (Figura 2A).

Para o rendimento de óleo essencial na segunda colheita não foi observada interação entre os fatores (teste F a 5\% de probabilidade). Assim, a adubação orgânica aplicada no plantio influenciou o rendimento de óleo de forma linear crescente, sendo que para cada $1,0 \mathrm{~kg}$ $\mathrm{m}^{-2}$ de esterco bovino adicionado no plantio, obteve-se uma resposta positiva de $7,16 \mathrm{~kg} \mathrm{ha}^{-1}$ na produtividade do óleo essencial. Já na adubação de cobertura aplicada após a primeira colheita também observou-se resposta linear e crescente, onde a cada $1,0 \mathrm{~kg} \mathrm{~m}^{-2}$ de esterco aplicado, houve aumento de 5,91 $\mathrm{kg} \mathrm{ha}^{-1}$ no rendimento do óleo essencial (Figura 2B).

Grande parte dos trabalhos com adubação orgânica tem mostrado que em solos mais adubados, tem se obtido maiores acúmulos de biomassa seca, o que reflete no rendimento de óleo essencial. Mesmo que o teor de óleo essencial diminua em relação ao aumento da adubação orgânica, geralmente, o aumento da produção de biomassa seca compensa o menor teor. No presente estudo, a adubação orgânica aplicada em doses crescentes não influenciou nos percentuais de óleo essencial em $M$. arvensis, mas o maior acúmulo de BSPA refletiu em maiores rendimentos de óleo essencial. Singh et al. (1988), também trabalhando com $M$. arvensis L., encontraram o maior rendimento de óleo essencial na maior dose de esterco bovino, devido à maior produção de biomassa seca. Já Mattos (2000), pesquisando cinco doses de esterco bovino $\left(0,2,4,6\right.$ e $\left.8 \mathrm{~kg} \mathrm{~m}^{-2}\right)$ em M. arvensis e Cruz (1999), estudando M. villosa, em experimento similar, observaram rendimentos crescentes de óleo essencial até a dose de $6 \mathrm{~kg} \mathrm{~m}^{-2}$, diminuindo na dose de $8 \mathrm{~kg} \mathrm{~m}^{-2}$, diferindo, dos resultados encontrados neste trabalho.

Os fatores que afetaram a produção de biomassa seca da parte aérea, afetaram também o rendimento de óleo essencial, como observado por diversos autores que encontraram maiores rendimentos de óleos essenciais com o aumento das doses de adubo orgânico (Ferreira et al., 2004; Sales et al., 2009; Silva et al., 2006; Singh et al., 1988; Souza et al., 2003). Assim, níveis mais elevados de nutrientes proporcionados pela adubação orgânica têm efeitos positivos no crescimento e no desenvolvimento das plantas.

Observa-se que a produção de biomassa seca e rendimento de óleo essencial de Mentha arvensis foram ob- tidos nas maiores dosagens de adubação orgânica, tanto no plantio $\left(10 \mathrm{~kg} \mathrm{~m}^{-2}\right)$ como em cobertura $\left(7,5 \mathrm{~kg} \mathrm{~m}^{-2}\right)$.

\section{AGRADECIMENTOS}

À CAPES, pela concessão da bolsa de estudos. Ao CNPq pela bolsa de produtividade e apoio técnico e à FAPEMIG pelo auxilio financeiro (PRONEX).

\section{REFERÊNCIAS}

BRILHO RC. 1969. Menta. Campinas: Coordenadoria de Assistência Técnica Integral. 34p.

CHAGAS JH; PINTO JEPB; BERTOLUCCI SKV; LANON FH; CHAGAS AB. 2007. Produção de biomassa seca, teor e rendimento de óleo essencial em plantas de Mentha arvensis L., em função da adubação orgânica em cobertura. In. CONGRESSO BRASILEIRO DE OLERICULTURA, 47. Resumos... Porto Seguro: SOB (CD-ROM).

CHATTOPADHYAY A; SUBRAHMANYAM K; SINGH DV. 1993. Recycling of nutrients in Japanese mint - assessment of soil fertility and crop yield. Fertilizer Research 35: 177-181.

CHAVES FCM; MATTOS SH; INNECCO R. 1998. Adubação orgânica em hortelãrasteira (Mentha $\mathrm{x}$ villosa Huds). Horticultura Brasileira 16, n. 1, (Resumo, 070).

CFSEMG - COMISSÃO DE FERTILIDADE DO SOLO DO ESTADO DE MINAS GERAIS. 1999. Recomendações para o uso de corretivos efertilizantes em Minas Gerais: $5^{a}$ Aproximação. Viçosa: CFSEMG, 359p.

COSTA LCB; PINTO JEBP; CASTRO EM; BERTOLUCCI SKV; CORREA RM; REIS ES; ALVES PB; NICULAU ES. 2008. Tipos e doses de adubação orgânica no crescimento, no rendimento e na composição química do óleo essencial de elixir paregórico. Ciência Rural 38: 2173-2180.

CRUZ GF. 1999. Desenvolvimento de sistema de cultivo para hortelã-rasteira (Mentha $x$ villosa Huds.). Fortaleza: UFC. 35p (Tese mestrado).

DUARTE MC; FIGUEIRA GM; SARTORATTO A; REHDER VL; DELARMELINA C. 2005. Anti-Candida activity of Brazilian medicinal plants. Journal of Ethnopharmacology 97: 305-311.

FERREIRA DF. 2003. SISVAR (Sistema para Análise de Variância) para Windows, versão 4.2. Lavras: DEX/UFLA.

FERREIRA MM; MOTTA MB; PINTO JEBP; CASTRO EM. 2004. Crescimento e alocação de biomassa de plantas de vinca (Catharanthus roseus (L.) G. Don) em função da adubação orgânica e época de colheita. Revista Brasileira de Plantas Medicinais 6: 72-76.

GARLET TMB; SANTOS OS; MEDEIROS SLP; MANFRON PA; GARCIA DC; SINCHAK SS. 2007. Crescimento e teor de óleo essencial 
de mentas com diferentes concentrações de potássio na solução nutritiva. Horticultura Brasileira 25: 230-237.

KALRA A; SINGH HB; PANDEY R; SAMAD A; PATRA NK; KUMAR S. 2004. Diseases in mint: causal organisms, distribution and control measures. Journal of Herbs, Spices \& Medicinal Plants 11:71-91.

KOEPPEN W. 1948. Climatologia. Tradução: Pedro RH. Perez. Buenos Aires, Gráfica Panamericana, $478 \mathrm{p}$.

KOTHARI R. 2005. The Indian essential oil industry. Perfumer and flavorist 30: 46-50.

MATTOS SH. 2000. Estudos fitotécnicos da Mentha arvensis L. var. Piperacens Holmes como produtora de mentol no Ceará. Fortaleza: UFC. 98p. (Tese doutorado).

OLIVEIRA JÚNIOR AC; FAQUIN V; PINTO JEBP. 2006. Efeitos de calagem e adubação no crescimento e nutrição de arnica. Horticultura Brasileira 24: 347-351.

PAULUS D; MEDEIROS SLP; SANTOS OS; MANFRON PA; PAULUS E; FABBRIN E. 2007. Teor e qualidade do óleo essencial de menta (Mentha arvensis L.) produzida sob cultivo hidropônico e em solo. Revista Brasileira de Plantas Medicinais 9: 80-87.

RAM D; RAM M; SINGH R. 2006. Optimization of water and nitrogen application to menthol mint (Mentha arvensis L.) through sugarcane trash mulch in a sandy loam soil of semi-arid subtropical climate. Bioresource Technology 97: 886-893.

RAM M; KUMAR S. 1997. Yield improvement in the regenerated and transplanted mint Mentha arvensis by recycling the organic wastes and manures. Bioresource Technology 59: 141-149.

RODRIGUES CR; FAQUIN V; TREVISAN D; PINTO JEBP; BERTOLUCCI SKV; RODRIGUES TM. 2004. Nutrição mineral, crescimento e teor de óleo essencial da menta em solução nutritiva sob diferentes concentrações de fósforo e épocas de coleta. Horticultura Brasileira 22: 573-578.

SALES JF; PINTO JEBP; BOTREL PP; SILVA FG; CORREA RM; CARVALHO JG. 2009. Germinação de sementes, crescimento da planta e composição química do óleo essencial de Hyptis marrubioides EP1., Lamiaceae. Bioscience Journal 25: 60-68.

SANGANEIRA S. 2005. Vibrant India. Perfumer and flavorist 30: 24-34.

SILVA FG; PINTO JEBP; CARDOSO MG; SALES JF; MOL DJS; DIVINO SP. 2006. Influence of manure and fertilizer on Baccharis trimera (Less) DC. growth and essential oil yield. Journal of Herbs, Spices \& Medicinal
Plants 12: 1-1.

SINGH H; SINGH V; RAM P. 1988. Effect of manure and fertilizers on herb, oil and yield of Mentha arvensis L. Indian Journal of Agronomy 33: 287-289.

SOUZAAH; MARACAJÁ PB; SOUZA JUNIOR JC; VASCONCELOS WE; MAIA CE. 2003. Produção de biomassa na parte aérea da erva cidreira (Melissa spp.) em função de doses de esterco bovino, húmus de minhoca, composto orgânico e NPK em casa de vegetação. Revista de Biologia e Ciência da Terra 3: 1-8.

SOUZA MAA; ARAÚJO OJL; FERREIRA MA; STARK EMLM; FERNANDES MS; SOUZA SR. 2007. Produção de biomassa e óleo essencial de hortelã em hidroponia em função de nitrogênio e fósforo. Horticultura Brasileira 25: 41-48.

SRIVASTAVA RK; SINGH AK; KALRA A; TOMAR, VKS; BANSAL RP; PATRA DD; CHAND S; NAQVI AA; SHARMA S; KUMAR S. 2002. Characteristics of menthol mint Mentha arvensis cultivated on industrial scale in the Indo-Gangetic plains. Industrial crops and products 15: 189-198.

VALMORBIDA J; BOARO CSF. 2007. Growth and development of Mentha piperita L. in nutrient solution as affected by rates of potassium. Brazilian Archives of Biology and Technology 50: 379-384. 